\title{
Pharmacokinetic Comparison of Two Gabapentin Formulations in Healthy Volunteers
}

\author{
Wen Yao Mak ${ }^{1 *}$, Siew Siew Tan², Jia Woei Wong ${ }^{2}$, Siaw Kuen Chin², Ai Boey Lim², Ean Peng Soon², Irene Looi ${ }^{1}$ and Kah Hay Yuen \\ ${ }^{1}$ Clinical Research Centre, Hospital Seberang Jaya, Jalan Tun Hussein Onn, 13700 Seberang Jaya, Pulau Pinang, Malaysia \\ ${ }^{2}$ Hovid Research Sdn Bhd, USM Laboratory Room 024, Kompleks EUREKA, Universiti Sains Malaysia, 11800 USM, Pulau Pinang, Malaysia
}

\begin{abstract}
The objective of the study was to establish bioequivalence between a local generic against the innovator product of gabapentin $300 \mathrm{mg}$. The study design was a standard two-way crossover, open-label, randomised and single dose study in 24 healthy male volunteers under fasting condition. The washout period was 7 days between both periods to allow adequate drug elimination. Liquid chromatography tandem mass spectrometry was utilised to determine gabapentin concentration in plasma. Non-compartmental model was used to analyse $T_{\max }, C_{\max }, A C_{0-1}, A C_{0-\infty}, t_{1 / 2}$ and $k_{e}$. Potential adverse events were closely monitored and recorded throughout the study. The study found all pharmacokinetic parameters were within the bioequivalence limit of $80.00 \%-125.00 \%$, with minimum side effects. In conclusion, the generic product was bioequivalent to the innovator product.
\end{abstract}

Keywords: Bioequivalence; Bioavailability; Pharmacokinetic; Gabapentin

\section{Introduction}

Gabapentin (1-(aminomethyl)cyclohexaneacetic acid) is licensed for use in Malaysia as adjunct therapy to intractable partial epilepsy and treatment for neuropathic pain [1]. Gabapentin is a chemical analogue to gamma-aminobutyric acid (GABA) but it does not interact with GABA receptors nor does it interfere with GABA metabolism [2]. Instead it is found that gabapentin is a ligand to the $\alpha 2 \delta$ subunit of the voltage-gated calcium channel, where it acts by disrupting calcium channel trafficking thereby blocking new synapse formation [3].

Plasma concentration of gabapentin does not show proportionality with the dose ingested [4]. This is mainly due to the saturable absorption pathway of gabapentin, namely a zero-order pharmacokinetic process [5,6]. Gabapentin does not bind to plasma protein [7] and it is not metabolized in humans [8]. In addition, gabapentin exhibit zero-order absorption pharmacokinetic, and poor oral bioavailability (absolute bioavailability varies from $60 \%$ to $33 \%$ with increasing dose from 900 to $3600 \mathrm{mg}$ daily) [7]. The peak plasma concentration of gabapentin is reached within 2 to 3 hours after ingestion of an immediate-release formulation [9] whereby administration with food does not appreciably affect the absorption. Nonetheless, high-protein meal (consisting of total $80 \mathrm{~g}$ protein) significantly increases $\mathrm{C}_{\text {max }}$ by $36 \%$, and to a lesser extent, increases AUC by $11 \%$. [10]. Gabapentin has an elimination half-life of 5 to 7 hours [9].

The purpose of the current study was to assess the rate and extent of absorption of two gabapentin formulations, and to establish bioequivalence between both products.

\section{Method}

\section{Study protocol}

The study was approved by the Malaysian Medical Research Ethics Committee (MREC), and was conducted according to the Malaysian Good Clinical Practice (GCP) guideline and consistent with the Helsinki Declaration. The study consisted of two parts: the clinical phase and the bioanalytical phase. The prior was conducted at the Clinical Trial Unit, Seberang Jaya Hospital (Penang, Malaysia) while the latter was conducted in the bioanalytical laboratory, Hovid Research Private
Limited, Universiti Sains Malaysia (Penang, Malaysia). All investigators involved in the clinical phase were GCP-certified. Written informed consent was obtained from all volunteers prior to the conduct of any study related procedures.

\section{Test and reference product}

The test product was manufactured by Hovid Berhad, Malaysia (Neuran $300 \mathrm{mg}$ Capsule) while the reference product was Neurontin $300 \mathrm{mg}$ capsule produced by Pfizer Pharmaceuticals LLC, Vega Baja, United States. (Reference product: batch number G98395, expiry date January 2016; Test product: batch number BD11641, expiry date November 2016).

\section{Participants}

A screening procedure was conducted to identify eligible volunteers to participate in this study. The inclusion/exclusion criteria were listed as below:

Inclusion criteria: Male healthy volunteers who were between the age of 21 to 55 years old, with a Body Mass Index (BMI) from 18.5 to 29.9 and in good physical condition as determined by medical history and laboratory tests. The laboratory tests included renal function tests (serum creatinine and blood urea nitrogen), liver function tests (total protein, total albumin, total globulin, aspartate transaminase, and alanine transaminase), full blood count (haemoglobin, red cell count, total white cell count, haematocrit, and platelet) and fasting blood glucose test. All volunteers were able to understand the study procedure, and had given informed consent to participate in the study.

*Corresponding author: Wen Yao Mak, Clinical Research Centre, Hospital Seberang Jaya, Jalan Tun Hussein Onn, 13700 Perai, Pulau Pinang, Malaysia, Tel: 04-3827333 Ext 511; Fax: 04-3902192; E-mail: makwy@crc.gov.my

Received December 06, 2015; Accepted December 31, 2015; Published January 07, 2016

Citation: Mak WY, Tan SS, Wong JW, Chin SK, Lim AB, et al. (2016) Pharmacokinetic Comparison of Two Gabapentin Formulations in Healthy Volunteers. J Bioequiv Availab 8: 055-058. doi:10.4172/jbb.1000267

Copyright: $\odot 2016$ Mak WY, et al. This is an open-access article distributed under the terms of the Creative Commons Attribution License, which permits unrestricted use, distribution, and reproduction in any medium, provided the original author and source are credited. 
Exclusion criteria: Significant clinical deviation from norm as observed by study clinician, a history of or suspicion of drug or alcohol dependence, requirement of tranquilizers, sedatives, chronic medications (for hypertension and diabetes, anti-platelet agents, antiepileptics, analgesics, opioids, psychotropic, antibiotics, monoamine oxidase inhibitors), a history or presence of organ dysfunction, history or presence of bone-marrow depression, serious blood disorders, cardiac arrhythmias, cardiovascular disease, stroke, bronchospasm, diabetes mellitus, renal disease, liver disease, thyrotoxicosis, parkinsonism, benign prostatic hypertrophy, epilepsy or migraine, and malignancy. Volunteers were excluded as well if they exhibit hypersensitivity towards the study drug gabapentin, or had participated in other study or donated blood within 8 weeks prior to study date, who smoke more than 10 cigarettes daily, or unable to neither understand the study protocol nor give informed consent.

\section{Study design}

The study was designed as an open-label, randomized-sequence, single-dose, two-treatments, two-way crossover bioequivalence study. The participants were randomly assigned into one of two groups, where the first group will receive the test $(\mathrm{T})$ and reference (R) formulation in the T/R sequence; while the second group will receive both formulations in the $\mathrm{R} / \mathrm{T}$ sequence. Randomization of participants was conducted with the randomization program. A washout period of at least 7 days between two periods was implemented to allow adequate elimination of study drug from the body.

All volunteers were recruited within one month period prior to the study date to ensure no significant changes to their physical condition.

All participants were required to stay in the clinical facility and undergo a 10-hour fasting prior to dosage administration. A single dose of either the test or reference formulation was administered by qualified pharmacist with $240 \mathrm{ml}$ of plain water, followed by a mouth check to ensure the dose was administered successfully. Access to water was prohibited for 1 hour before and after dosage administration, and all participants were requested to continue fasting until 4-hour post dosing. A total of 15 blood samples $(5 \mathrm{ml})$ were taken from each participants at 0 hour (pre-dose), 0.5, 1, 1.5, 2, 2.5, 3, 4, 5, 6, 8, 12, 26,24 , and 48 hours after ingestion of each formulation. A maximum of $5 \%$ deviation was allowed for the scheduled sampling time before being considered as protocol deviation. The blood samples were centrifuged at $3500 \mathrm{rpm}$ for 15 minutes immediately after collection, and subsequently transferred to separate glass containers where the samples were kept frozen at $-20^{\circ} \mathrm{C}$. Standardized, calorie-counted meals were provided at 4 - and 10-hour, while standardized snacks were provided at 8- and 13-hour. All food consumption was supervised whereby the participants were required to finish all food provided.

Vital signs such as blood pressure, pulse rate, respiratory rate and temperature were measured multiple times throughout the study period, and prior to subject discharge from the clinical facility. Study participants were advised to inform study clinicians if they experience any discomfort or adverse events.

\section{Analysis of plasma gabapentin}

Plasma concentration of gabapentin was analyzed with liquid chromatography-tandem mass spectrometry (LC/MS/MS). Before injection into the system, gabapentin was extracted from the plasma samples with direct deproteinization procedure. The bioanalytical process was subjected to validation before being implemented in the study.
The liquid chromatography component consisted of an Agilent 1200 Series Binary Pump (Agilent, Waldbronn, Germany), an Agilent 1200 Series Degasser (Agilent, Waldbronn, Germany), an Agilent 1200 Series Thermostatted Column Compartment (Agilent, Waldbronn, Germany) and a Agilent 1200 Series Instant Pilot (Agilent, Waldbronn, Germany). The tandem mass spectrometry component consisted of an Applied Biosystems API 3200 triple quadrupole mass spectrometer (Applied Biosystems/MDS SCIEX, Ontario, Canada) in positive electrospray ionization (ESI) mode. Data acquisition and analysis were performed with the software Analyst version 1.4.2 (Applied Biosystems/MDS SCIEX, Ontario, Canada).

The analytical column used was a Phenomenex Luna HILIC $200 \AA$ $(150 \times 2.0 \mathrm{~mm}$ id, $3 \mu \mathrm{m})$ (Phenomenex, USA), which was fitted with the SecurityGuard" HPLC Guard Cartridge System with a SecurityGuard Cartridge (HILIC, $4 \times 2.0 \mathrm{~mm}$ ID Guard) (Phenomenex, USA). The system was maintained at $30^{\circ} \mathrm{C}$. The mobile phase used was a mixture of $80.0 \%$ acetonitrile in $1 \mathrm{mM}$ ammonium formate buffer adjusted to $\mathrm{pH} 3.0$ with formic acid. The flow rate was set at $0.20 \mathrm{ml} /$ min isocratically. Tramadol was used as internal standard. Multiple reactions monitoring (MRM) was employed to monitor the transition $\mathrm{m} / \mathrm{z}$ 172.1->154.1 (gabapentin) and $\mathrm{m} / \mathrm{z} 264.3->58.1$ (tramadol). The samples were quantified using peak area.

\section{Pharmacokinetic analysis}

According to European Medicine Agency (EMA), two pharmacokinetic parameters should be analyzed: the area-underthe-concentration-time-curve from time zero to the last measurable concentration, $\mathrm{AUC}_{(0-t)}$ and maximum plasma concentration, $\mathrm{C}_{\max }$ [11]. The FDA guideline recommended additional parameter such as total area-under-the-concentration-time-curve, $\mathrm{AUC}_{(0-\infty)}$ and elimination half-life, $t_{1 / 2}$ [12]. The value of $\mathrm{AUC}_{(0-\mathrm{t})}$ was calculated with the trapezoidal formula, and the value of $\mathrm{AUC}_{(0-\infty)}$ was found by dividing the last measurable plasma drug concentration with the elimination rate constant $\left(\mathrm{k}_{\mathrm{e}}\right)$. $\mathrm{k}_{\mathrm{e}}$ was calculated from the terminal slope of the logarithmic transformed plasma concentrations with at least three concentration values, and the subsequent application of linear regression. The gabapentin half-life was calculated with the formula $\mathrm{t}_{1 / 2}=\ln 2 / \mathrm{k}$

Non-compartmental pharmacokinetic model was used to determine the parameter required. This was consistent with the recommendation by the EMA guideline [11].

\section{Statistical analysis}

Analysis of Variance (ANOVA) was used in the analysis of $\mathrm{AUC}_{0-\mathrm{t}}$, $\mathrm{AUC}_{0-\infty}$, and $\mathrm{C}_{\max }$. The data were logarithmically transformed prior to analysis, and the confidence interval of the difference between both formulations was calculated. This was then back-transformed to arithmetic scale. The terms used in the ANOVA model included sequence, subject within sequence, period and formulation.

In order to conclude bioequivalence between the two formulations, the $90 \%$ confidence interval of the ratio of test over reference formulation parameter $\left(\mathrm{AUC}_{0-\mathrm{t}}, \mathrm{AUC}_{0-\infty}\right.$, and $\mathrm{C}_{\max }$ ) should be within the acceptance interval of 80.00 to $125.00 \%$ [11-13].

\section{Results}

A total of 24 healthy volunteers were recruited into the study, and all completed both phases successfully. The participants' demographic distribution was shown in Table 1. 
Citation: Mak WY, Tan SS, Wong JW, Chin SK, Lim AB, et al. (2016) Pharmacokinetic Comparison of Two Gabapentin Formulations in Healthy Volunteers. J Bioequiv Availab 8: 055-058. doi:10.4172/jbb.1000267

\begin{tabular}{|l|c|}
\hline Characteristic & Value $(n=24)$ \\
\hline $\begin{array}{l}\text { Age, } \mathrm{y} \\
\text { Median } \\
\text { Interquartile Range }\end{array}$ & 28 \\
\hline Race, no. (\%) & 10.5 \\
Malay & $22(91.7)$ \\
Other & $2(8.3)$ \\
\hline Height, cm & \\
Median & 169 \\
Range & $162.5-176.5$ \\
\hline $\begin{array}{l}\text { Weight, kg } \\
\text { Median } \\
\text { Interquartile Range }\end{array}$ & 70.4 \\
\hline $\begin{array}{l}\text { Body mass index, } \mathrm{kg} / \mathrm{m}^{2} \\
\text { Median } \\
\text { Interquartile Range }\end{array}$ & 21.3 \\
\hline
\end{tabular}

Table 1: Demographic distribution of study participants.

\section{Tolerability}

Both formulations were very well tolerated. There was no reported serious adverse event during the study periods. Only one subject reported to experience giddiness during both study periods when he was administered both the test and reference products. Giddiness was a common side effects of gabapentin [2,14]. The subject fully recovered from the side effects within 24 hours. Another subject experienced mild flu-like symptoms during the washout period (after administration of the reference products during first study period). However the side effects was deemed not drug related.

\section{Pharmacokinetic and bioequivalence analysis}

Figure 1 depicted the mean plasma concentration versus time profile for both the test and reference gabapentin formulation, superimposed on each other. The related pharmacokinetic parameter derived was shown in Table 2. There was no statistical difference detected between the logarithmic transformed values of $\mathrm{AUC}_{0-\mathrm{t}}$ $(p=0.5895), \mathrm{AUC}_{0-\infty}(p=0.5187)$ and $\mathrm{C}_{\max }(p=0.5866)$. The value for $\mathrm{T}_{\max }$ showed no significant difference as well $(p=0.7712)$.

The $90 \%$ confidence interval of the ratio of test over reference formulation was all within the acceptance values (80.00-125.00\%). The confidence intervals were 0.9197-1.1393 $\left(\mathrm{AUC}_{0-\mathrm{t}}\right), 0.9258-1.1358$ $\left(\mathrm{AUC}_{0-\infty}\right)$ and 0.9598-1.1630 ( $\left.\mathrm{C}_{\text {max }}\right)$.

\section{Method validation and analysis of plasma concentration}

The analysis of gabapentin plasma concentration was performed in a Good Laboratory Practice (GLP) certified facility. The analysts were blinded to the treatment randomization even though the study was an open label study. The analytical method was fully validated. Several key aspects were assessed including the selectivity, linearity and range of calibration curve, accuracy, precision and analyte recovery, and also the stability of the analyte. Accuracy was defined as the percentage of measured concentration against the actual (spiked) concentration. Precision was denoted the coefficient of variation.

The calibration curve was linear over the range of 78.1-10000.0 $\mathrm{ng} / \mathrm{ml}$ with a correlation coefficient of at least 0.99 . For within-day validation, mean measured concentration did not deviate by more than $\pm 11.3 \%$ from the actual value for all six concentrations measured. The coefficient of variation values were not more than $7.6 \%$. For betweenday validation, the mean measured concentrations did not deviate by more than $\pm 13.4 \%$ from all concentration measured, with a coefficient of variation or less than $9.5 \%$. The absolute recovery of gabapentin ranged from 74.3 to $81.1 \%$. The limit of quantification was set at 78.1 $\mathrm{ng} / \mathrm{ml}$ and the limit of detection was set at $39.1 \mathrm{ng} / \mathrm{ml}$. No endogenous peak was found at the retention time of gabapentin and tramadol respective (2.4 and 2.1 minutes).

Stability testing indicated that gabapentin was stable for at least 3 freeze-thaw cycles, and when stored between $-15^{\circ} \mathrm{C}$ and $-22^{\circ} \mathrm{C}$, gabapentin was stable for at least 2 months. Short term stability study showed that gabapentin in plasma was stable for 6 hours in room temperature. All analysis was completed within 2 months period from the start of the sampling collection date.

\section{Discussion}

Gabapentin is widely used to treat partial epilepsy in Malaysia, and is recommended as second-line adjunct therapy for patients who have poor epileptic control on first-line antiepileptic drug (AEDs) or intolerant to them [15]. Rising costs of innovator drugs has prompted many patients to seek generic substitutions.

Based on the bioequivalence acceptance criteria, it was concluded that the test product was bioequivalent to the reference (innovator) products. Although there were concerns with regards to generic substitution of AEDs, the Medicines and Healthcare Products Regulatory Agency (MHRA) has produced a report which stated that no specific precaution is needed when prescribing gabapentin. The clinicians were allowed to prescribe generically [16].

The values of the intra-subject coefficient of variation (CV) for $\mathrm{AUC}_{0-\mathrm{t}}, \mathrm{AUC}_{0-\infty}$ and $\mathrm{C}_{\max }$ were all under $30 \%$, as estimated using the mean square error of ANOVA analysis (18.5\%, $17.2 \%$ and $17.5 \%)$. Based on these values, it was concluded that the sample size of 24 subjects was sufficient to provide a power $(1-\beta)$ of more than $80 \%$,

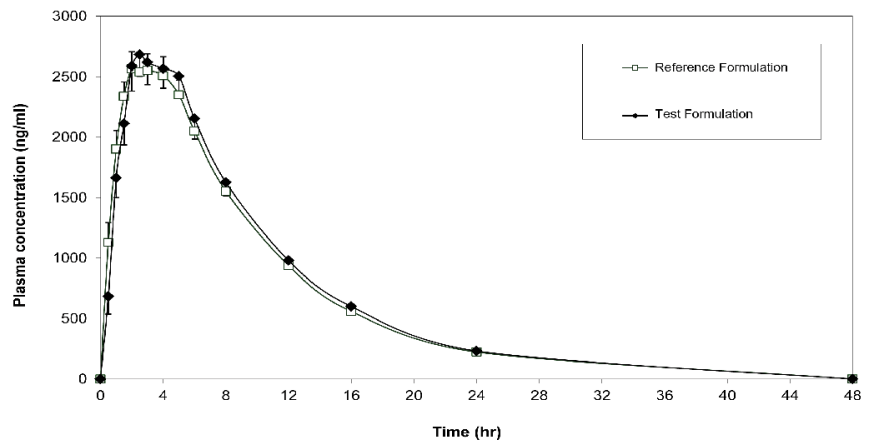

Figure 1: Mean gabapentin plasma concentration-time profile for test versus references formulations (300 mg capsule). Mean \pm sem. $n=20$.

\begin{tabular}{|c|c|c|c|}
\hline Parameters & $\begin{array}{c}\text { Test Formulation } \\
\text { Mean (SD) }\end{array}$ & $\begin{array}{c}\text { Reference Formulation } \\
\text { Mean (SD) }\end{array}$ & $\begin{array}{c}\text { Coefficient of } \\
\text { variation } \\
\text { (\% CV) }\end{array}$ \\
\hline $\mathrm{AUC}_{0-\mathrm{t}}(\mathrm{hr} . \mathrm{ng} / \mathrm{ml})$ & $28445(8021.6)$ & $27717(6417.2)$ & 28.2 \\
\hline $\mathrm{AUC}_{0-\infty}(\mathrm{hr} . \mathrm{ng} / \mathrm{ml})$ & $30431(8452.1)$ & $29609(6989.6)$ & 27.8 \\
\hline $\mathrm{C}_{\max }$ & $3073(803.3)$ & $2904(596.2)$ & 26.1 \\
\hline $\mathrm{T}_{\max }$ & $3.1(1.35)$ & $3.1(1.38)$ & $\mathrm{N} / \mathrm{A}$ \\
\hline $\mathrm{T}_{1 / 2}$ & $5.9(1.10)$ & $5.8(0.59)$ & $\mathrm{N} / \mathrm{A}$ \\
\hline
\end{tabular}

Abbreviation: AUC, Area Under the Concentration-Time Curve; AUC $C_{0-1}$, AUC from Dosing to Last Sampling Time; $\mathrm{AUC}_{0-\infty}$, Total AUC; $\mathrm{C}_{\max }$, Maximum Plasma Concentration; $T_{\max }$, Time Required to Achieve $C_{\max } ; t_{1 / 2}$, Half-Life; N/A, Not Applicable

Table 2: Pharmacokinetic parameters and matching coefficient of variation for gabapentin after single dose oral administration. 
Citation: Mak WY, Tan SS, Wong JW, Chin SK, Lim AB, et al. (2016) Pharmacokinetic Comparison of Two Gabapentin Formulations in Healthy Volunteers. J Bioequiv Availab 8: 055-058. doi:10.4172/jbb.1000267

given the type 1 error rate $(\alpha)$ was 0.05 . The $\mathrm{CV}$ values were crucial for sample size calculation, and were found comparable to values reported in other studies $[4,17]$.

\section{Conclusion}

The study concluded that the test formulation was bioequivalent to the reference formulation.

\section{Acknowledgement}

The authors thank all medical staffs at the Clinical Research Centre, Seberang Jaya Hospital who contributed to the study.

\section{Declaration of Personal Interest}

Kah Hay Yuen was the advisor to the R\&D department of Hovid Ltd, the manufacturer of the test formulation. Siew Siew Tan, Jia Woei Wong, Siaw Kuen Chin, Ai Boey Lim and Ean Peng Soon were employees to Hovid-Research Sdn Bdn, an independent research company which was affiliated with Hovid Ltd. Wen Yao Mak and Irene Looi did not have any conflict of interest to disclose.

\section{Declaration of Funding Interest}

This study was supported by Hovid Ltd

\section{References}

1. Ministry of Health Malaysia (2014) Ministry of Healthy Drug Formulary. Ministry of Health Malaysia.

2. Chadwick D (1994) Gabapentin. Lancet 343: 89-91.

3. Dickens D, Webb SD, Antonyuk S, Giannoudis A, Owen A, et al. (2013) Transport of gabapentin by LAT1 (SLC7A5). Biochem Pharmacol 85: 16721683.

4. Gidal BE, DeCerce J, Bockbrader HN, Gonzalez J, Kruger S, et al. (1998) Gabapentin bioavailability: Effect of dose and frequency of administration in adult patients with epilepsy. Epilepsy Res 31: 91-99.

5. Bockbrader HN, Wesche D, Miller R, Chapel S, Janiczek N, et al. (2010) A comparison of the pharmacokinetics and pharmacodynamics of pregabalin and gabapentin. Clin Pharmacokinet 49: 661-669.
6. Stewart BH, Kugler AR, Thompson PR, Bockbrader HN (1993) A saturable transport mechanism in the intestinal absorption of gabapentin is the underlying cause of the lack of proportionality between increasing dose and drug level in plasma. Pharm Res 10: 276-281.

7. Bockbrader HN, Wesche D, Miller R, Chapel S, Janiczek N, et al. (2010) A comparison of the pharmacokinetics and pharmacodynamics of pregabalin and gabapentin. Clin Pharmacokinet 49: 661-669.

8. Berry DJ, Beran RG, Plunkeft MJ, Clarke LA, Hung WT (2003) The absorption of gabapentin following high dose escalation. Seizure 12: 28-36.

9. Gordi T, Hou E, Kasichayanula S, Berner B (2008) Pharmacokinetics of gabapentin after a single day and at steady state following the administration of gastric-retentive- extended-release and immediate-release tablets: A randomized, open-label, multiple-dose, three-way crossover, exploratory study in hea. Clin Ther 30: 909-916.

10. Gidal BE, Maly MM, Budde J, Lensmeyer GL, Pitterle ME, et al. (1996) Effect of a high-protein meal on gabapentin pharmacokinetics. Epilepsy Res 23: 71-76.

11. European Medicines Agency (2010) CPMP/EWP/QWP/1401/98 REV. 1/ CORR $^{* *}$-Guideline on the Investigation of Bioequivalence. London 1-27 .

12. Kimanani E, Stypinski D, Curtis G, Stiles M, Heessels P, et al. (2000) A contract research organization's response to the new FDA guidances for bioequivalence/bioavailability studies for orally administered drug products. $J$ Clin Pharmacol 40: 1102-1108.

13. Malaysia Ministry of Health (2000) Malaysian guidelines for the conduct of bioavailability and bioequivalence studies 1-28.

14. Neurontin ${ }^{\circledast}$ (2009) New York 1-29.

15. Epilepsy Council Malaysian Society of Neurosciences (2010) Consensus Guidelines on the Management of Epilepsy 2010.

16. Medicines and Healthcare Products Regulatory Agency (2013) Formulation switching of antiepileptic drugs: a Report on the Recommendations of the Commission on Human Medicines from July 2013.

17. Tjandrawinata RR, Setiawati E, Putri RS, Yunaidi DA, Amalia F, et al. (2014) Single dose pharmacokinetic equivalence study of two gabapentin preparations in healthy subjects. Drug Des Devel Ther 8: 1249-1255. 